\title{
The HPA axis and GABA-Glutamate Systems as Potential Antidepressant Targets in Prostate Cancer
}

\author{
Christopher F. Sharpley ${ }^{1, *}$ and David R. H. Christie ${ }^{2}$ \\ ${ }^{1}$ Brain-Behavior Research Group, University of New England, NSW, Australia \\ ${ }^{2}$ Brain-Behavior Research Group, Bond University, Qld, \& Premion, Qld, Australia
}

\begin{abstract}
A common treatment for Prostate Cancer includes androgen-deprivation for a period of months prior to radiation or surgery. Some data suggest that this may exacerbate the already elevated depression levels of these patients, arguing for concomitant application of antidepressant therapy. However, the various waves of antidepressants developed in the last 40 years have shown only arguable specific efficacy over placebo, plus significant side-effects which may hinder treatment decision-making and compliance. This paper outlines two emerging and potential pathways for development of new pharmacological agents for depression that hold promise of helping patients to reduce their depressive symptomatology.
\end{abstract}

Keywords: Antidepressants, efficacy, GABA, glutamate, HPA.

\section{THE HPA AXIS AND GABA-GLUTAMATE SYSTEMS AS POTENTIAL ANTIDEPRESSANT TARGETS IN PROSTATE CANCER}

The adverse effects of depression (including bipolar depression) on physical health, relationships and cognitive performance are well reported [1-4]. The damaging effects of depression are further indicated by the finding that it poses as great a risk for mortality as does smoking, even when related health factors such as blood pressure, alcohol intake, cholesterol and social status are taken into account [5]. Depression is the principal contributor to the Total Disease Burden [6], and predicted to become the second leading cause of mental illness by $2020[7,8]$.

Receiving a diagnosis of prostate cancer $(\mathrm{PCa})$ is often accompanied by elevated depression [9-11], with the incidence of this psychological disorder at about 26\% [12], four or five times the national average for non-PCa men of similar age [13]. When combined with the fact that the risk for developing prostate cancer by age 85 years is 1 in 5 in Australia [14], the possibility of getting $\mathrm{PCa}$ and being depressed is significant. There is also evidence that elevated depression in the PCa patient group can have powerful and extended effects by hindering treatment compliance and decision-making [15], perhaps reducing the longer-term success of treatment and further limiting patients' chances of recovery [16]. For example, depression has been shown to cause up to $48 \%$ of some cancer patients to withdraw from treatment [17], thus constituting a major medical issue as well as reducing patient well-being.

*Address correspondence to this author at the Brain-Behavior Research Group, University of New England, NSW. PO Box 378, Coolangatta, Qld, 4225. Tel: 6175599 4778; E-mail: csharpley@onthenet.com.au
Bearing these facts in mind, it is of particular relevance to consider the usage rates and effects of anti-androgen therapy hormone treatment $(\mathrm{HT})$, which is commonly given to PCa patients for 18 months and may even be applied for several years to reduce the size of tumors and symptomatic progress $[18,19]$. For example, in a study of $4,892 \mathrm{PCa}$ patients who underwent either radical prostatectomy or external beam radiation therapy, $1,105(21 \%)$ also received HT [20]. However, in their examination of $36,496 \mathrm{PCa}$ patients' records in 1999, Zelefsky and colleagues [21] noted that the incidence of HT was between $31 \%$ and $79 \%$, depending upon the risk status of the patients, and that the use of HT had increased from an average of 8\% in 1994 to $51 \%$ of PCa patients in 1999. It may be that usage rates of HT vary across samples but, at least from these data, it might be concluded that the prescription of HT for PCa patients is not uncommon and therefore justifies consideration of its efficacy and side effects.

Described as a "cornerstone treatment of advanced prostate cancer" in Sharifi, Gully and Darhut's 2005 review of the effectiveness of HT from data published during the preceding 40 years [22], HT can reduce bone pain, fractures, spinal cord compression and ureteral obstruction as well as PCa tumor size, but may not improve long-term survival when used in cases of advanced PCa. By comparison, when used with radiation therapy in less severe PCa, HT does show a survival benefit [22], and may be a treatment of choice. However, some side effects are also apparent, including hot flushes, reduction in bone mineral deposit density, osteoporosis and anemia [22]. HT may also cause or exacerbate fatigue [22] and deficits in memory and cognitive processing, contributing to the development of depression [23-26]. PCa patients undergoing HT also report reduced energy and poorer sexual and urinary function [27] than $\mathrm{PCa}$ patients undergoing other treatments [28]. These and other 
side effects may be more closely related to lowered testosterone rather than HT alone [29], a finding that reflects other data regarding the link between hypotestosteronaemia and depression in older men [30], although there are also data suggesting that the link between lowered testosterone and depression may be reciprocal [31], perhaps confounding the issue of mood disorders in older PCa patients who receive $\mathrm{HT}$.

Whichever direction the relationship between HTinduced lowered testosterone and depression moves, $\mathrm{PCa}$ patients are significantly more likely to experience mood disorders, particularly depression, than other men of the same age [32], and this may be a result (at least in part) of the application of HT. Therefore, physicians who prescribe HT (for very defensible reasons) may also need to be aware of the increased likelihood of their PCa patients developing depression. As well as being unpleasant, depression can also have deleterious effects on patients' ability to make decisions about their treatment and develop effective lifestyle strategies to deal with the other side effects of HT that they experience and which were mentioned earlier in this paper. As well as the mood-effecting outcomes of HT, there are also data suggesting that $\mathrm{PCa}$ patients experience significant fear, anxiety and consequent feelings of helplessness which may also lower their mood independently of HT [33-35].

While careful noting of patient behavior during consultations, and/or formal psychological or psychiatric assessment, can inform physicians about the affective state of their patients, treatment of the depression that (a) occurs with greater frequency among PCa patients than their healthy peers, (b) may be related to the shock of receiving a diagnosis of $\mathrm{PCa}$, and (c) can be exacerbated by HT, requires care. Such treatment may be undertaken by application of pharmacological agents in the form of antidepressants, as well as via psychotherapy techniques. However, although some data indicate that selective serotonin reuptake inhibitors may reduce hot flushes produced by anti-androgen therapy, as well as combat general depressive symptoms [36], the efficacy of traditional pharmacological antidepressant therapies is not absolute [37].

\section{ANTIDEPRESSANTS: MECHANISMS, SIDE EFFECTS, EFFICACY}

Traditional antidepressants are based upon the "monoamine hypothesis", that explains depression as arising from a depletion of the neurotransmitters serotonin, noradrenalin and dopamine in the brain due to the re-uptake of these neurotransmitters in the post-synapse by monoamine oxidase. This is plausible because serotonin constitutes the largest cohesive neurotransmitter system in the brain and innervates all brain areas [38], and changes to serotonin influence the core behavioral and somatic functions that underlie depression in laboratory animal studies, including appetite, sleep, sex, pain responses, body temperature and circadian rhythm [39]. In addition, human postmortem studies have shown lowered levels of serotonin in depressed patients [40-42], although serotonin depletion studies indicate that reduced serotonin may be a necessary, but not a sufficient, condition for depression [38, 43]. Noradrenalin is also a major neurotransmitter, and modulates functioning of the prefrontal cortex (which uses working memory to regulate behavior and attention), as well as having an important role in the acquisition of emotionally-arousing memories. Dopamine also modulates activity in brain areas involved with reward and motivation, working memory and attention [44], and has been inculcated in the development of depression [45] although postmortem and depletion studies have been equivocal [38]. Thus, depletions in serotonin, noradrenalin and dopamine have been the principal targets for antidepressants.

However, antidepressants that act via blocking the effects of monoamine oxidase have been shown to have only limited efficacy in large trials. For example, Stahl [46] commented that only about two-thirds of actual (non-clinical trial) patients receiving antidepressants actually showed reduced depressive symptoms. Further, a major meta-analytic review of the effectiveness of antidepressants revealed that antidepressants did show a statistically significant superiority over placebo, but that the difference in test scores (1.7 points on the 52-point Hamilton Depression Scale) was "clinically negligible" [47; p. 1, 48]. More recently, Pigott, Leventhal, Alter and Boren [49] reviewed four major meta-analysis of the efficacy of antidepressants and supported Kirsch et al.'s comment that the difference between medication and placebo was marginal. While some authors have criticized the use of meta-analysis and the randomized placebocontrolled studies on which they are based, suggesting that these are not valid replicates of actual clinical practice [50] and that those outcome measures of change in depression are "arbitrary" (p. 451 [50]), there are few data which show strong support for the efficacy of traditional antidepressants. When added to the finding that studies which reported positive outcomes from drug treatment for depression were between five and 16 times more likely to be published than reports of negative or unequivocal outcomes $[49,51,52]$ the likelihood of research which supports Kirsch and colleagues' conclusions regarding the lack of efficacy of antidepressants, is dramatically increased. Finally, antidepressants elevate the levels of monoamine neurotransmitters within a few days but do not alter mood for several weeks [53], suggesting that they may regulate longer-term trophic effects that are actually responsible for depleted synaptic monoamines [46].

In addition to the uncertain efficacy of traditional antidepressants, most of these treatments also have significant side-effects for patients, including hypotension, tremors, insomnia, increased appetite (and weight gain), dry mouth, blurred vision, urinary retention, headaches, acute hypertension, sedation, confusion and problems with motor coordination, many of which pass after a few weeks at about the same time as the antidepressant effect begins to take place. Other lasting side-effects are constipation and urinary retention, drowsiness and difficulty concentrating. Some patients experience ventricular dysrhythmias, nausea, anorexia, insomnia, loss of libido and failure to reach orgasm [54]. Some antidepressants have also been implicated in elevated risk of patient suicide [55].

Clearly, there are some problems in the prescription of traditional antidepressants to $\mathrm{PCa}$ patients who, like most cancer sufferers, experience a major shock and challenge to their equanimity, fear, and confusion, all of which may contribute to the development of depression. However, the 
application of HT, with its significant side effects upon patient mood, makes PCa patients (and other patients that receive HT) a particular focus for the development of more effective pharmacological treatments for depression. Two potential pathways to such antidepressant treatments are the HPA axis and the GABA/glutamate neurotransmitter systems, and each of these will be briefly described below.

\section{NEWER DEVELOPMENTS}

\section{HPA Axis}

One of the more recently-investigated pathways to treat depression is via re-establishment of normal function in the hypothalamic-pituitary-adrenal (HPA) axis, generally regarded as the biological focus of an individual's vulnerability to depression [56]. The HPA axis responds to stress by secreting corticotropin-releasing hormone $(\mathrm{CRH})$ from the hypothalamus which then instigates the secretion of adrenocorticotropic hormone (ACTH) from the pituitary into the bloodstream, which in turn causes the synthesis and release of cortisol from the adrenal cortex [57]. Chronic stress can therefore lead to elevated levels of cortisol, which also contributes to an elevated risk of depression [58]. Higher levels of its trophic precedents CRH and ACTH, plus cortisol itself, are consistently seen within depressed patients $[59,60]$, with some data [61] indicating that up to $80 \%$ of depressed patients have elevated cortisol levels. Gold, Drevets and Charney [62] described several pathways between elevated cortisol and depression, including alteration of prefrontal cortex function, amygdala and hypothalamus hyperactivity and reductions in volume and function of the hippocampus.

Antidepressant treatments based upon HPA axis function have included antiglucocorticoids to inhibit cortisol synthesis (aminoglutethimide, ketoconazole, metyrapone) [63], with some supportive data from animal studies [64] and with depressed patients [65]. CRH has been targeted by Gold, Licinio, Wong and Croussos [66] and Holsboer [60] in studies using the CRH-antagonist R121919, which has been shown to reduce major depressive disorder in clinical Phase I studies $[67,68]$, although these initial data require evaluation in full clinical trials.

\section{GABA and Glutamate}

One other possible avenue for future development of antidepressant medications may lie with the neurotransmitters glutamate and gamma-aminobutyric acid (GABA). Malfunction of these neurotransmitters upsets the balance between their excitatory (glutamate) and inhibitory (GABA) effects of upon brain synaptic activity, supporting potential links to depression via loss of cognitive ability [69], neuron and glial apoptosis [70], dysregulation of growth factors in the brain [71], interference in dopamine firing [72] and decreased serotonin and noradrenalin expression [73]. Several research studies have demonstrated that depressed patients experience malfunction of GABA and glutamate systems [72, 74-79] and that glutamatergic drugs which target the receptors AMPA, NMDA and KA may enhance synaptic signalling within the glutamate system, but no trials of the effects of medications based upon these data have yet been reported [80]. Other potential research foci for development of new antidepressants lie in examination of brain-derived neurotrophic factor [81], selective serotonin receptors [82], cytokines [83], the anti-epileptic Pregabalin [84], and a concentration upon neuronal plasticity rather than neurogenesis [85].

\section{IMPLICATIONS FOR CLINICAL PRACTICE}

HT remains a treatment of choice for at least one in five PCa patients and most probably more. While there are sound data supporting its application in many cases of PCa, HT also has significant side effects that may instigate or exacerbate patient feelings of depression. Because lowered mood states can detract from patients' decision-making and lifestyle management of their disease and its treatment, consideration of possible use of antidepressant therapy is important for clinicians. However, these therapies also have significant side effects and their efficacy may be questioned.

Therefore, although still in their infancy as regards clinical use, the development of newer antidepressant medications based upon HPA-axis and GABA models holds promise for the clinical oncologist in several ways. First, as $\mathrm{PCa}$ increases in incidence with an aging population, it may be expected that greater numbers of patients will present with this disease, and that at least a proportion of them will experience depression as a result of the shock of receiving a diagnosis of cancer, as well as via the side effects of HT. Second, the application of a wider range of hormone-based therapies (including anti-androgens) can also be expected to increase, not only because they are well-established in the treatment of metastatic disease, but also because recent randomized trial data [86] have shown their efficacy in neoadjuvant (prior to radiotherapy) and adjuvant (following radiotherapy) treatments, particularly improvements in the length of time patients are free from biochemical and other evidence of recurrent disease. The use of ultrasensitive PSA testing following initial treatment by surgery or radiotherapy has led to earlier detection of recurrent disease and the early use of hormone-based therapies in that setting is under investigation [87]. With these newer hormonal-based treatments, new challenges to psychological patient wellbeing may also arise, as well as those currently presented by HT. Third, if the initial findings from HPA-axis and GABA development trials continue, antidepressants based on these models may be relatively free of the deleterious side effects noted above for traditional antidepressants and, as such, may constitute an alternative pharmacotherapy for the treatment of depression among PCa patient groups.

Therefore, development and clinical trialing of some of these new approaches to antidepressants briefly mentioned here may lead to significant improvements in patients' psychological well-being as well as avoidance of some of the complications from existing antidepressants that may adversely affect cancer treatment outcomes (such as poor treatment compliance and premature withdrawal from treatment). If their effectiveness is demonstrated via traditional clinical evaluation protocols, these screening tools and interventions could become a routine part of prostate cancer treatment, as well as suggesting new lines of research in other cancers, particularly breast cancer, in which the use of $\mathrm{HT}$ is also common. 


\section{REFERENCES}

[1] Druss BG, Rosenheck RA. Patterns of health care costs associated with depression and substance abuse in a national sample. Psychiatr Serv $1999 ; 50(2)$ : 214-8.

[2] Judd LL, Paulus MP, Wells KB, Rapaport MH. Socioeconomic burden of subsyndromal depressive symptoms and major depression in a sample of the general population. Am J Psychiatry 1996; 163: 1411-7.

[3] Lyness JM, Heo M, Datto CJ, et al. Outcomes of minor and subsyndromal depression among elderly patients in primary care settings. Ann Int Med 2006; 144(7): 496-504.

[4] Nutt D. Anxiety and depression: Individual entiteis or two sides of the same coin? Int J Psychiatr Clin Pract 2004; 8: 19-24.

[5] Mykletun A, Bjerkeset O, Øverland S, Prince M, Dewey M, Stewart R. Levels of anxiety and depression as predictors of mortality: the HUNT study. Br J Psychiatry 2009; 195: 118-25.

[6] Ustun TB, Ayuso-Mateos JL, Chatterji S, Mathers C, Murray CJL. Global burden of depressive disorders in the year 2000. Br J Psychiatry 2004; 184: 386-92.

[7] Murray CJ, Lopez AD. Alternative projections of mortality and disability by cause 1990-2020: global burden of disease study. Lancet 1997; 349: 1498-504.

[8] WHO. Cross-national comparisons of the prevalences and correlates of mental disorders. WHO International Consortium in Psychiatric Epidemiology. B World Health Organ 2001; 78: 413426.

[9] Bennet G, Badger TA. Depression in men with prostate cancer. Oncol Nurs Forum 2005; 32(3): 545-56.

[10] Katz M. Quality of life for men with prostate cancer. Cancer Nurs 2007; 30(4): 302-8.

[11] Sharpley CF, Bitsika V, Christie DRH. Psychological distress among prostate cancer patients: fact of fiction? Clin Med Oncol 2008; 2: 563-72.

[12] Sharpley CF, Christie DRH. An analysis of the psychometric profile and frequency of anxiety and depression in Australian men with prostate cancer. Psychooncology 2007; 16: 660-7.

[13] Henderson S, Andrews G, Hall W. Australia's mental health: an overview of the general population survey. Aust N Z J Psychiatry 2000; 34(2): 197-205.

[14] Coory M, Baade P. Urban-rural differences in prostate cancer mortality, radical prostatectomy and prostate-specific antigen testing in Australia. Med J Aust 2005; 182: 112-5.

[15] Christie K, Meyerowitz B, Giedzinska-Simons A, Gross M, Agus D. Predictors of affect following treatment decision-making for prostate cancer: conversations, cognitive processing, and coping. Psychooncology 2009; 18: 508-14.

[16] Thomas B, Thomas I, Nandamohan V, Nair M, Pandey M. Screening for distress can predict loss of follow-up and treatment in cancer patients: results of development and validation of the Distress Inventory for Cancer Version 2. Psychooncology 2009; 18: 524-33.

[17] Fallowfield L. Acceptance of adjuvant therapy and quality of life issues. Breast 2005; 14: 612-6.

[18] Brawer M. Hormonal therapy for prostate cancer. Rev Urol 2006; 8: S35-S47.

[19] Mottet N, Prayer-Galetti T, Hammerer P, Kattan M, Tunn U. Optimizing the outcomes and quality of life in the hormonal treatment of prostate cancer. BJU Int 2006; 98: 20-7.

[20] Tsai HK, D'Amico AV, Sadetsky N, Chen M-H, Carroll PR. Androgen deprivation therapy for localized prostate cancer and the risk of cardiovascular mortality. J Natl Cancer Inst 2007; 99(20): 1516-24.

[21] Zelefsky MJ, Moughan J, Owen J, Zietman AL, Roach M, Hanks GE. Changing trends in national practice for external beam radiotherapy for clinically localized prostate cancer: 1999 patterns of care survey for prostate cancer. Int J Radiat Oncol Biol Phys 2004; 59(4): 1053-61.

[22] Sharifi N, Gulley JL, Dahut WL. Androgen deprivation therapy for prostate cancer. JAMA 2005; 294(2): 238-44

[23] Schwandt A, Garcia J. Complications of androgen deprivation therapy in prostate cancer. Curr Opin Urol 2009; 19: 322-6.

[24] Miyamoto H, Messing E, Chang C. Androgen deprivation therapy for prostate cancer: current status and future prospects. Prostate 2004; 61: 332-53
Pirl WF, Greer J, Goode MJ, Smith MR. Prospective study of depression and fatigue in men with advanced prostate cancer receiving hormone therapy. Psychooncology 2007; 17(2): 148-53.

[26] Pirl WF, Siegel GI, Goode MJ, Smith MR. Depression in men receiving androgen deprivation therapy for prostate cancer: a pilot study. Psychooncology 2002; 11: 518-23.

[27] Basaria S, Lieb J II, Tang AM, et al. Long-term effects of androgen deprivation therapy in prostate cancer patients. Clin Endocrinol 2002; 56(6): 779-86.

[28] Lubeck DP, Grossfeld GD, Carroll PR. The effect of androgen deprivation therapy on health-related quality of life in men with prostate cancer. Urology 2001; 58(2, Supplement 1): 94-9.

[29] Dacal K, Sereika SM, Greenspan SL. Quality of life in prostate cancer patients taking androgen deprivation therapy. J Am Geriatr Soc 2006; 54(1): 85-90.

[30] Seidman SN, Walsh BT. Testosterone and depression in aging men. Am J Geriatr Psychiatry 1999; 7(1): 18-33.

[31] Schweiger U, Deuschle M, Weber B, et al. Testosterone, gonadotropin, and cortisol secretion in male patients with major depression. Psychosom Med 1999; 61(3): 292-6.

[32] Sharpley C, Bitsika V, Christie D. Psychological distress among prostate cancer patients: fact or fiction? Clin Med Oncol 2008; 2 563-72.

[33] Sharpley C, Bitsika V, Christie D. Helping prostate cancer patients understand the causes of anxiety and depression: comparing cancer-caused vs patient response events. J Men's Health Gender 2009; 6: 345-53.

[34] Sharpley C, Bitsika V, Christie D. "Why I feel bad": Refinement of the effects of Prostate cancer upon lifestyle questionnaire and an initial exploration of its links with anxiety and depression among prostate cancer patients. Psychooncology 2010; 19: 839-46.

[35] Sharpley C, Bitsika V, Christie D. Incidence and nature of anxietydepression comorbidity in prostate cancer patients. J Men's Health Gender 2010; 7: 125-34

[36] Naoe M, Ogawa Y, Shichiho T, Fuji K, Fukagai T, Yoshida H. Pilot evaluation of selective serotonin reuptake inhibitor antidepressants in hot flash patients under androgen-deprivation therapy for prostate cancer. Prostate Cancer Prostatic Dis 2006; 9 : 275-8.

[37] Kirsch I. The emperor's new drugs: exploding the antidepressant myth. The Bodley Head: London 2009.

[38] Delgardo P, Morena F. Neurochemistry of mood disorders. In: Stein DK, Kupfer DJ, Schatzberg AF, Eds. The textbook of mood disorders. American Psychiatric Publishing Inc: Washington DC 2006; pp. 101-16.

[39] Maes M, Meltzer $\mathrm{H}$. The serotonin hypothesis of major depression In: Bloom FE, Kupfer DJ, Eds. Psychopharmacol: The fourth generation of progress. Raven: New York 1995; pp. 933-44.

[40] Perry EK, Marshall EF, Blessed G, Tomlinson BE, Perry RH. Decreased imipramine binding in the brains of patients with depressive illness. Br J Psychiatry 1983; 142: 188-92.

[41] Stanley M, Virgilio J, Gershon S. Tritiated imipramine binding sites are decreased in the frontal cortex of suicides. Science 1982; 216: 1337-9.

[42] Stockmeier CA. Involvement of serotonin in depression: evidence from postmortem and imaging studies of serotonin receptors and the serotonin transporter. J Psychiatr Res 2003; 37: 357-73.

[43] Delgardo P. How antidepressants help depression: mechanisms of action and clinical response. J Clin Psychiatry 2004; 65: 25-30.

[44] Chen L, Zhuang X. Transgenic mouse models of dopamine deficiency. Ann Neurol 2003; 54: S91-S102.

[45] Willner P. Dopamine and depression: a review of recent evidence, I: empirical studies. Brain Res 1983; 6: 211-24.

[46] Stahl S. Stahl's essential psychopharmacology. $3^{\text {rd }}$ ed. Cambridge University Press Cambridge 2008

[47] Kirsch I, Moore TJ, Scoboria A, Nicholls SS. The Emperor's New Drugs: An Analysis of Antidepressant Medication Data Submitted to the U.S. Food and Drug Administration. Prev Treat 2002; 5: Article 23.

[48] Moncrieff J, Kirsch I. Efficacy of antidepressants in adults. Br Med J 2005; 331: 155-7.

[49] Pigott H, Leventhal A, Alter G, Boren J. Efficacy and effectiveness of antidepressants: current status of research. Psychother Psychosomat 2010; 79: 267-79. 
[50] Moller H-J, Maier W. Evidence-based medicine in psychopharmacotherapy: possibilities, problems and limitations. Eur Arch Psychiatr Clin Neurosci 2009; 260(1): 25-39.

[51] Rising K, Bacchetti P, Bero L. Reporting bias in drug trials submitted to the Food and Drug Administration: A review of publication and presentation. PLoS Med 2008; 5: e217.

[52] Turner E, Matthews A, Linardatos E, Tell R, Rosenthal R. Selective publication of antidepressant trials and its influence on apparent efficacy. N Engl J Med 2008; 358: 252-60.

[53] Anderson AK, Spencer DD, Fullbright RK, Phelps EA. Contribution of the anteromedial temporal lobes to the evaluation of facial emotion. Neuropsychology 2000; 14(4): 526-36.

[54] Rang HP, Dale MM, Ritter J, Flower RJ. Pharmacology. $6^{\text {th }}$ ed. Elsevier: Philadelphia 2007.

[55] Gunnell D, Saperia J, Ashby D. Selective serotonin reuptake inhibitors (SSRIs) and suicide in adults: meta-analysis of drug company data from placebo controlled, randomised controlled trials submitted to the MHRA's safety review. Br Med J 2005; 330: 3858.

[56] Sapolsky RM. Glucocorticoids and hippocampal atrophy in neuropsychiatric disorders. Arch Gen Psychiatr 2000; 57(10): 92535 .

[57] Guyton A, Hall J. Textbook of med physiol, $11^{\text {th }}$ ed. Elsevier: Philadelphia 2006

[58] de Kloet ER, Fitzsimons CP, Datson NA, Meijer OC, Vreugdenhil E. Glucocorticoid signaling and stress-related limbic susceptibility pathway: about receptors, transcription machinery and microRNA. Brain Res 2009; 1293: 129-41.

[59] Carroll BJ, Greden JF, Feinberg M, et al. Neuroendocrine evaluation of depression in borderline patients. Psychiatry Clin North Am 1981; 4(1): 89-99.

[60] Holsboer F. Therapeutics for depression and anxiety disorders. Drug Discov Today: Ther Strat 2004; 1(1): 105-9.

[61] Thomson F, Craighead M. Innovative approaches for the treatment of depression: targeting the HPA Axis. Neurochem Res 2008; 33 : 691-707.

[62] Gold PW, Drevets WC, Charney DS. New insights into the role of cortisol and the glucocorticoid receptor in severe depression. Biol Psychiatry 2002; 52: 381-5.

[63] Seidman S. Targeting peptide and hormonal systems. In: Stein D, Kupfer D, Schatzberg AF, Eds. The textbopk of mood disorders. American Psychiatric Publishing Inc: Washington, DC 2006; pp. 305-16.

[64] Surget A, Saxe M, Leman S, et al. Drug-dependent requirements of hippocampal neurogenesis in a model of depression and of antidepressant reversal. Biol Psychiatry 2008; 64(4): 293-301.

[65] Ising M, Zimmerman US, Kunzel HE, et al. High-Affinity CRF, Receptor Antagonist NBI-34041: Preclinical and Clinical Data Suggest Safety and Efficacy in Attenuating Elevated Stress Response. Neuropsychopharmacology 2007; 32: 1941-9.

[66] Gold PW, Licinio J, Wong M-L, Chrousos GP. Corticotropin releasing hormone in pathophysiology of melancholic and atypical depression and in the mechanism of action of antidepressant drugs. Ann N Y Acad Sci 1995; 771: 716-29.

[67] Held $\mathrm{K}$, Kunzel HE, Ising $\mathrm{M}$, et al. Treatment with the $\mathrm{CRH}_{1^{-}}$ receptor-antagonist R121919 improves sleep-EEG in patients with depression. J Psychiatr Res 2004; 38: 129-36.

[68] Künzel HE, Zobel AW, Nickel T, et al. Treatment of depression with the CRH-1 receptor antagonist R121919: endocrine changes and side effects. J Psychiatr Res 2003; 37: 525-33.
[69] Cryan JF, Kaupmann K. Don't worry 'B' happy!: a role for GABA receptors in anxiety and depression. Trends Pharmacol Sci 2005; 26(1): 36-43.

[70] Rajkowska G, Miguel-Hidalgo JJ, Wei J, et al. Morphometric evidence for neuronal and glial prefrontal cell pathology in major depression. Biol Psychiatry 1999; 45: 1085-98.

[71] Evans SJ, Choudary PV, Neal CR, Vawter MP, Tomita H, Lopez $\mathrm{JF}$, et al. Dysregulation of the fibroblast growth factor system in major depression. Proc Natl Acad Sci USA 2004; 101(43): 15506-11.

[72] Choudary P, Molnar M, Evans SJ, et al. Altered cortical glutamatergic and GABAergic signal transmission with glial involvement in depression. Proc Natl Acad Sci USA 2005; 102: 15653-8.

[73] Muller N, Schwartz MJ. The immune-mediated alteration of serotonin and glutamate: Towards an integrated view of depression. Mol Psychiatry 2007; 12: 988-1000.

[74] Auer DP, Putz B, Kraft E, Lipinski B, Schill J, Holsboer F. Reduced glutamate in the anterior cingulate cortex in depression: an in vivo proton magnetic resonance spectroscopy study. Biol Psychiatry 2000; 47: 305-13.

[75] Bhagwagar Z, Wylezinska M, Jezzard P, Evans J, Ashworth F, Sule A. Reduction in occipital cortex $\gamma$-aminobutric acid concentrations in medication-free recovered unipolar depressed and bipolar subjects. Biol Psychiatry 2007; 61: 806-12.

[76] Mason GF, Anand A, Sanacora G, et al. Different relationships among cortical amino acids in unipolar and bipolar depression. Proc Int Soc Magn Reson Med 2001; 9: 557.

[77] Sanacora G, Mason GE, Rothman DL, et al. Reduced $\gamma$-aminobutyric acid levels in depressed patients determined by proton magnetic resonance spectroscopy. Arch Gen Psychiatry 1999; 56: 1043-7.

[78] Sanacora G, Mason GF, Krystal JH. Impairment of GABAergic transmission in depression: new insights from neuroimaging studies. Crit Rev Neurobiol 2000; 14(1): 23-45.

[79] Sanacora G, Gueorguieva R, Epperson CN, et al. Subtype-specific alterations of $\gamma$-aminobutyric acid and glutamate in patients with major depression. Arch Gen Psychiatry 2004; 61: 705-13.

[80] Sen S, Sanacora G. Major depression: emerging therapeutics. Mount Sinai J Med 2008; 75: 205-25.

[81] Groves JO. Is it time to reassess the BDNF hypothesis of depression? Mol Psychiatry 2007; 12: 1079-88.

[82] Svenningsson P, Tzavara ET, Qi H, et al. Biochemical and behavioral evidence for antidepressant-like effects of $5-\mathrm{HT}_{6}$ receptor stimulation. J Neurosci 2007; 27(15): 4201-9.

[83] Raison CL, Borisov A, Majer M, et al. Activation of central nervous system inflammatory pathways by interferon-alpha: relationship to monomines and depression. Biol Psychiatry 2009; 65: 296-303.

[84] Showraki M. Pregabalin in the treatment of depression. J Psychopharmacol 2007; 21(8): 883-4.

[85] Bessa JM, Ferreira D, Melo I, et al. The mood-improving actions of antidepressants do not depend on neurogenesis but are associated with neuronal remodeling. Mol Psychiatry 2009; 14(8): 764-73.

[86] Bolla M, de Reijke TM, Van Tienhoven G, et al. Duration of Androgen Suppression in the Treatment of Prostate Cancer. N Engl J Med 2009; 360(24): 2516-27.

[87] Shen S, Lepor H, Yaffee R, Taneja SS. Ultrasensitive serum prostate specific antigen nadir accurately predicts the risk of early relapse after radical prostatectomy. J Urol 2005; 173(3): 777-80. 